\title{
Impact Assessment: Perception of physiotherapy faculty: A pilot study
}

\author{
Y. Praveen Kumar, ${ }^{1, *}$, Y Pallavi Praveen Kumar ${ }^{2}$ \\ ${ }^{\mathbf{1}}$ Professor\& HOD, Dept. of Cardio-Respiratory Physiotherapy, ${ }^{2}$ Associate Professor \& HOD, Dept. of Community \\ Physiotherapy, VSPM College of Physiotherapy, Nagpur, Maharashtra, India
}

*Corresponding Author:

Email: praveenkwhy@gmail.com

\begin{abstract}
Introduction: Impact assessment links evidence and decision making according to world health organisation. Moreover Maharashtra University of Health Sciences had recently conducted the impact assessment of physiotherapy colleges and V.S.P.M'S college of physiotherapy was one of the first physiotherapy institute to undergo this process which prompted the idea of undertaking the research with an aim to understand the perceptions of physiotherapy faculty in regards to impact assessment.

Material and Methods: Descriptive questionnaire based study was carried out on physiotherapy faculties of 2 out of the 4 colleges existent in Nagpur which had undergone for impact assessment process. The faculties who volunteered to participate in the study were provided with questionnaires for understanding the perceptions of impact assessments .The questionnaire consisted of 10 closed ended questions which were rated according to 5 point likert scale and 2 open ended questions which were assessed according to specific key themes

Results: $100 \%$ of the faculty perceived that impact assessment requires co-ordinated work and $81 \%$ felt it created a new learning experience ,but variations of perceptions existed in relation to replacement of local inspection with impact assessment .Majority of the faculty were not knowing about impact assessment before 2018 .

Conclusions: Impact assessment helps in improving quality of physiotherapy colleges although it is a time consuming process.
\end{abstract}

Keywords: Impact assessment, Physiotherapy, Perception.

\section{Introduction}

Impact Assessments is a type a evaluation which are basically formal in nature and procedurally evidence-based that assess the economic, social, and environmental effects of public policy. ${ }^{1}$ This type of assessments have been initially and widely utilized in policy making in the organization for Economic Cooperation and Development ccountries (OECD ) and the European Commission as it helps is improving legislation. $^{2}$ Literatures have also shown that it can focus on specific themes. ${ }^{3}$ Through the available literatures it is known that impact assessment is pointed towards global assessments, policy impact assessment, strategic environmental assessment, social impact assessments and gender impact assessments.

Impact assessment links evidence and decision making according to world health organization. ${ }^{4}$ In Indian scenario the Maharashtra state government had a project and desire for grading the health science colleges affiliated to Maharashtra university of health science on same lines of national assessment accreditation council (NAAC) so that students can opt for better choices based on grading of colleges .Initially homeopathy and ayurveda colleges underwent for impact assessment inspections and recently inspections was conducted for the impact assessment of physiotherapy colleges ${ }^{5}$ and V.S.P.M'S college of physiotherapy was one of the first physiotherapy institute to undergo this process which prompted the idea of undertaking the research.

\section{Aim and Objective}

To understand the perceptions of physiotherapy faculty towards impact assessment. Studying the perceptions of physiotherapy faculty for impact assessment based on the responses obtained from the structured questionnaire.

\section{Material and Methods}

Descriptive questionnaire based study was carried out on physiotherapy faculties of 2 out of the 4 colleges existent in Nagpur which had undergone for impact assessment process. Requisite permissions were obtained before commencement of the study Ethical clearance was obtained from the Institutional Ethical Committee.

In all there were 24 faculties, 17 faculties belonged to V.S.P.M's college and 7 from Datta Meghe College of Physiotherapy. Universal sampling was utilized so that responses could be obtained from all the faculties for understanding the perceptions of impact assessments.

The designations of faculties were principal professors 2, Professor 1, 7 associate professors and 14 assistant professors. The participants who were willing to voluntarily participate were included provided they fulfilled the inclusion criteria formed the source for the data.

\section{Inclusion criteria:}

1. Physiotherapy faculty

2. Present on the day of survey 
Exclusion criteria: 1. Researcher and co- researcher of the current study

In all 17 faculties formed the sample for the study from among the 24 and they were explained in relation to nature of the study and later on provided with the questionnaire and adequate time was provided for filling up of questionnaires

The questionnaire consisted of 10 closed ended questions which were rated according to 5 point likert scale and 2 open ended questions which were assessed according to specific key themes based on the responses obtained from the participants.

\section{Data analysis}

The raw data obtained from the study which was in the form of 5 point likert scale as strongly agree, agree, neither agree nor disagree, disagree and strongly disagree for each of the 10 questions. Further analysis was carried out by collapsing the responses into 3 components as agree (strongly agree \& agree), disagree (strongly disagree \& disagree) and neither agree nor disagree based on the perceptions of physiotherapy faculty and was entered in the Microsoft Excel sheet 2007. Statistical analysis was carried out by utilizing Epi-Info software. The study being descriptive in nature the responses were expressed in percentages. The two open ended questions were analyzed according to the specific key themes.

\section{Results}

The results obtained from the study provides the perceptions of the physiotherapy faculty aged between 26-50 years with a mean age of $35.25 \pm 5.98$ for 10 open ended questions which is represented in bar diagram as shown below:

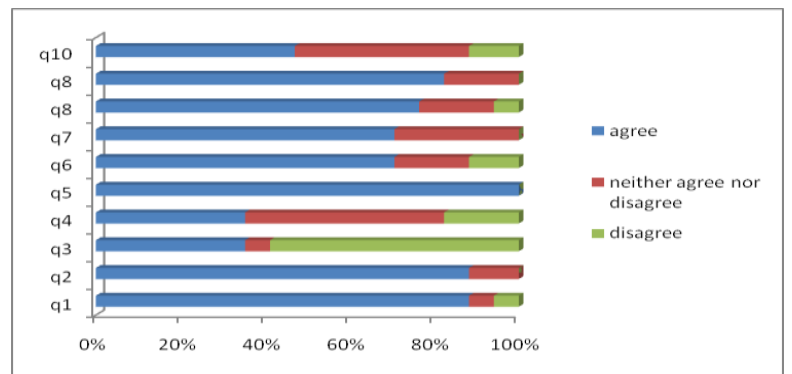

Fig. 1: Bar diagram representing the perceptions of physiotherapy faculty

$88.23 \%$ agreed that impact assessment is an effective way for inspecting physiotherapy colleges and it helps to improve the quality of physiotherapy colleges'. Majority of the faculty did not know about impact assessment before 2018 as only $35.29 \%$ knew impact assessment before 2018. $47.05 \%$ neither agreed nor disagreed that impact assessment reflects true assessment of physiotherapy colleges. $100 \%$ of the faculty perceived that impact assessment requires coordinated work from all faculties $.70 .58 \%$ perceived that impact assessment is a time consuming process but agreed that the impact assessment scores should be used to rank physiotherapy colleges. $82.35 \%$ felt it created a new learning experience, but variations of perceptions existed in relation to replacement of local inspection with impact assessment with $47.05 \%$ agreeing and $41.17 \%$ neither agreeing nor disagreeing and $11.76 \%$ disagreeing.

The pie chart below indicates things liked and disliked about impact assessments.

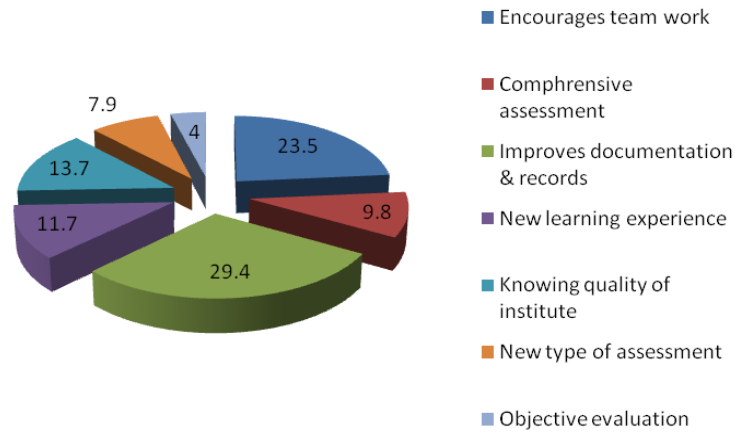

Fig. 2: Pie diagram representing the things liked about impact assessment

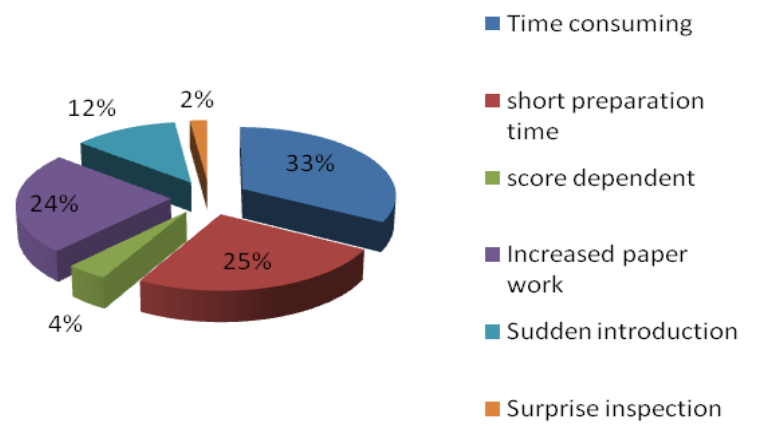

Fig. 3: Pie diagram representing the things disliked about impact assessment 


\section{Discussion}

The results of the study clearly indicate that the objective of the study "understanding the perceptions of physiotherapy faculty by responses obtained from the questionnaire" was achieved. Although the responses were obtained from faculties belonging to two different physiotherapy colleges but this would not have impacted the study as both the colleges underwent for same type of inspection in the form of impact assessment and it was a structured format .

$70.83 \% \quad(n=17)$ of the available 24 staff participated in the study and all the 17 staff who participated in the study promptly handed over the questionnaires back after completely filling it up. 100\% response rate of the participating staff was obtained which is much higher than the acceptable response rates for questionnaires which is $80 \%{ }^{6,7}$ Nigel Lendemann in $2018^{7}$ has written that a high response rate $(>80 \%)$ from a small sample is preferable to a low response rate from a large sample and further wrote that survey's response rate is seen as an important indicator of survey quality.

The reason for the high response rates could be attributed to the fact that the questionnaire was a short questionnaire with only 12 questions with 10 closed ended and two open ended questions. It has been observed that on an average a 17\% drop in response rate when survey has more than 12 questions $^{7}$ and hence in the current study 12 questions were used to understand the perceptions .Moreover as it was an internal survey it usually receives $20 \%$ higher response rates.

It is also to note that the perceptions of the faculties were varying emphasizing the fact that individual variations are bound to be there and therefore should adhere to the principle of majority when implementing policy decisions in the interest of the profession. Although the impact assessment is time consuming process but still then it helps in providing grades to colleges and institutions which further promotes the institutions and colleges to strive for better quality thereby enhancing the quantification on quality institutes.

\section{Conclusion}

It can thus be concluded from the perceptions of physiotherapy faculty that impact assessment helps in improving quality of physiotherapy colleges although it is a time consuming process . Thereby emphasizing the fact that impact assessments could be a part and parcel of future inspections for grading of institutions and a step forward to replace the traditional local inspections in years to come.

\section{Impact}

The study is indicating that impact assessments have been well accepted and this type of assessments facilitates for newer methods towards improving the quality of physiotherapy colleges in a structured fashion. More over it has created a new learning phenomenon in the area of grading of physiotherapy colleges.

\section{Limitations}

The limitation of the study was that it did not include the faculties from all physiotherapy colleges affiliated to Maharashtra University of health sciences so as to further generalize the findings.

\section{Acknowledgement}

The authors thank the management of V.S.P.M. College of Physiotherapy, Mr. Nayse for statistical support.

\section{References}

1. Adelle, Camilla; Weiland, Sabine. "Policy assessment: the state of the art". Impact Assessment and Project Appraisal. 2012;30(1):25-33. doi:10.1080/14615517.2012.663256

2. Jacob, Klaus; Ferretti, Johanna; Guske, Anna-Lena; Turnpenny, John; Jordan, Andrew; Adelle, Camilla (2011). "Sustainability in Impact Assessments A Review of Impact Assessment Systems in selected OECD countries and the European Commission" (PDF). OECD. SG/SD(2011)6/FINAL. Retrieved 2012 12-10.

3. Impact assessment From Wikipedia, the free encyclopedia available from https://en.wikipedia.org/wiki/Impact_assessment this page was last edited on 10 May 2018, at 10:11 (UTC).

4. WHO, Impact assessment - World Health Organization available from http://www.who.int/heli/impacts/en/

5. Finally maharashtras medical colleges to be graded available from

https://timesofindia.indiatimes.com/city/mumbai/finall $\mathrm{y}$-maharashtras-medical-colleges-to-begraded/articleshow/64071323.cms

6. $\quad$ Evans, SJ. "Good surveys guide" (PDF). BMJ 1991;302(6772):302-3. doi:10.1136/bmj.302.6772.302. PMC 1669002. PMID 2001503

7. What's the average survey response rate? [2018 benchmark ... available from https://surveyanyplace.com/average-survey-responseratel

8. Altman, DG; Bland, JM (Feb 2007). "Missing data". BMJ 2007;334(7590):424. doi:10.1136/bmj.38977.682025.2C. PMC 1804157. PMID 17322261 . 